\title{
SCALE MORPHOLOGY, ARRANGEMENT AND MICRO-ORNAMENTATION IN XENOCHROPHIS PISCATOR (SCHNEIDER), NAJA NAJA (LINN), AND ERYX JOHNI (RUSSELL)
}

\author{
Priya Joseph ${ }^{1}$, Joe Prasad Mathew ${ }^{2}$ and V.C. Thomas ${ }^{2}$

\begin{abstract}
${ }^{1}$ Department of Zoology, Devamatha College, Kuravilangad, Kerala 686633, India
${ }^{2}$ Research \& Post Graduate Department of Zoology, St. Berchmans' College, Changanacherry, Kerala 686101, India

Email: ${ }^{1}$ jopmat@ rediffmail.com (corresponding author)
\end{abstract}

plus web supplement of 1 page

\begin{abstract}
An investigation was carried out to study the scale morphology, arrangement and micro-ornamentation in three Indian snakes - Xenochrophis piscator, Naja naja and Eryx johni to understand their role, if any, in regulating locomotion and its use as a taxonomic tool.

KEYWORDS

Eryx johni, micro-ornamentation, Naja naja, scale morphology, Xenochrophis piscator.
\end{abstract}

Among the different functions of epidermis, the most important role is to limit the exchange of water and electrolytes between the organism and its environment. In this context reptiles have attracted attention because they possess scales. Sweat glands are absent in reptiles and water loss in the form of vapour is passive through the respiratory system, but mainly through the skin. The water loss from skin is controlled or limited by the presence of scales.

The microstructure of the surface of reptilian scales is highly variable. Price (1982) observed this difference in snakes while Rubial (1968) and Peterson (1984) noticed it in some lizards. These studies have showed that the diversity arises from variation in two character suites, the arrangement of epidermal cells and the micro-ornamentation or sculpturing of cell surfaces. Price (1982), Peterson (1984) and Peterson \& Bezy (1985) have also suggested that the surface sculpturing of reptilian scales have some taxonomic significance. Price (1982) concluded that the microdermatoglyphic patterns reflect phylogenetic relationships rather than ecological relationships. This study (Joseph, 2001) was initiated to determine whether the microdermatoglyphics seen on dorsal snake scales is infact a taxonomic tool or an indicator of animals ecology.

\section{Methodology}

Adult snakes of Naja naja and Eryx johni were collected from different regions of Thiruvanathapuram district, while Xenochrophis piscator were collected from Kuttanad region of Alappuzha district. Snakes selected belonging to each species were more or less of same size, viz: Eryx johni $81 \pm 1.86 \mathrm{~cm}$, Xenochrophis piscator $100.7 \pm 1.87 \mathrm{~cm}$ and Naja naja $129 \pm$ $1.80 \mathrm{~cm}$. Animals were well maintained in the animal house in cages for micro-dermatoglyphic studies.

Scales from dorsal region (vertebral scales), dorso-lateral region (costal scales) and ventral region (ventral scales) were selected for the study from each snake. Vertebral width, vertebral length, costal length, costal width, ventral length and ventral width of the scales were taken. Mean and coefficient of variation were calculated. Statistical analysis of locomotor performance was carried out by one-way classification of Analysis of Variance (Snedcor \& Cochran, $1967)$.

Scale samples were collected from each snake. Square centimetre sections of the epidermis were removed from dorsal, dorso-lateral and ventral regions of the body. Both loosened scales and intact skin sections were cleaned by ultrasonification and air dried at the end of the cleaning period. Cleaned scale samples were placed in 95\% ethyl alcohol and dehydrated through three changes of $100 \%$ ethanol ( $5 \mathrm{~min}$ each). All specimens were critical point dried in $\mathrm{CO}_{2}$ in a Polaron (Model 5100 ) critical point dryer. Dried specimens were mounted on aluminium mounts with Avery spot O'glue and were coated in a Polaron (model E5 100) magnetron sputtering device with $300^{\circ} \mathrm{A}$ of material from a $60 / 40$ gold-palladium target. All scales or skin specimens were viewed at $0^{\circ}$ tilt and $50 \mathrm{KV}$ with a Philips Leo 435 VP Scanning Electron Microscope (SEM). Specimens were examined at different magnifications.

\section{RESUlts}

Though scales are present in all snakes under study they differ in their morphology, arrangement and number among species (Table 1; Images A to $\mathrm{L}^{\mathrm{w}}$ ). Considering the morphology of scales, ventral scales are narrow in Eryx johni while broad in Xenochrophis piscator and Naja naja. The posterior edge of the ventral scales are found free at their tip and just overlaps the anterior edge of the preceding ventral scales in all the three snakes. In Naja naja the belly plates are broader (vertebral length) than that of the Xenochrophis piscator (Table 1). Dorsal scales seen in Eryx johni are dull (The glossy nature in the image is due to photographic procedures.), closely attached to the skin and hexagonal in shape like a benzene ring and are very small in size (In the intact skin, the scales are arranged closely overlapping each other. Hence only the lower half of each scale is visible externally, as seen in the photo.). In Xenochrophis piscator and Naja naja, dorsal scales are larger in size and they are smooth and polished. In Xenochrophis piscator the dorsal scales are oblong and hexagonal in shape and in Naja naja the dorsal scales are oval and elongate in shape. Dorsal scales are keeled (with a central ridge in each scale) in Eryx johni and Xenochrophis piscator but are not keeled in Naja naja. The keeled dorsal scales are prominent in Naja naja. Another noticeable feature is that these keeled scales are not

w See Images on the web at www.zoosprint.org

Manuscript 1382; (C) ZOO; Date of publication 21 November 2007 Received 22 June 2005; Revised received 15 October 2005; Finally accepted 15 October 2007 
seen in dorsolateral portion of Eryx johni and Xenochrophis piscator. Anals are single in Eryx johni and Naja naja but divided in Xenochrophis piscator. Subcaudals are entire in Eryx johni but divided in Xenochrophis piscator and Naja naja. The arrangement of dorsal scales is such that they are overlapping to one another in Xenochrophis piscator and Eryx johni but contiguous in Naja naja. Number of longitudinal rows of the scales on the back is different in these snakes. In Eryx johni, number of longitudinal rows of scales in the middle region of body is 52. In Xenochrophis piscator it is 19 and in Naja naja it is 20. Longitudinal rows of scales change in their number within the snake at different regions and between the species.

Ventral, vertebral and costal scales show variation in their length and width among the three snakes $(\mathrm{P}<0.01)$ (Table 1$)$. Ventral length shows a maximum range $(44 \mathrm{~mm})$ in Naja naja and a minimum range $(11 \mathrm{~mm})$ in Eryx johni. Ventral width is $7 \mathrm{~mm}$ in Xenochrophis piscator and $5.5 \mathrm{~mm}$ and $5 \mathrm{~mm}$ in Naja naja and Eryx johni respectively. Vertebral scale length is maximum in Naja naja $(7 \mathrm{~mm})$ and minimum in Eryx johni $(2 \mathrm{~mm})$. In Xenochrophis piscator, it is $5 \mathrm{~mm}$. Vertebral width varies between $3 \mathrm{~mm}$ in Xenochrophis piscator to $2 \mathrm{~mm}$ in Eryx johni and Naja naja. Naja naja shows maximum costal length of $7 \mathrm{~mm}$ and Eryx johni shows the minimum range of $4.0 \mathrm{~mm}$. Costal width ranges between $5.1 \mathrm{~mm}$ in Xenochrophis piscator to $4.0 \mathrm{~mm}$ in Eryx johni.

The micro-ornamentation studies of the scales using scanning electron microscope (SEM) in the three snakes reveal different sculpturing on the scale surface (Images A-Fw). These are not found to correlate with any of the descriptions for microornamentation pattern which are already available. However, they somewhat resemble a few patterns, so that this is considered as the subtypes of original ones. When considering microornamentation pattern it would be noteworthy to understand that there is no standardised terminology for scale microornamentation patterns. Hence the one which is described by Price $(1982)$ is considered as principle terminology in the present study.

The ventral and dorsal scale in Xenochrophis piscator (see Images $\mathrm{A}^{\mathrm{w}} \& \mathrm{~B}^{\mathrm{w}}$ ) shows a plicated style which is considered as type of plicate pattern, seen among certain types of aquatic snakes. The Naja naja scales (see Images $\mathrm{E}^{\mathrm{w}} \& \mathrm{~F}^{\mathrm{w}}$ ) have flakelike ridges piled upon one another irregularly. This is considered as a subtype of the cristate pattern. In Eryx johni, scales (see Images $\mathrm{C}^{\mathrm{w}} \& \mathrm{D}^{\mathrm{w}}$ ) have channelled grooves which extend longitudinally from one side to another uniformly. In between the channels there are ridges of uniform size. This type closely resembles the canaliculate pattern.

\section{Discussion}

All the taxa examined have a porous pattern on their scales. In addition to the porous pattern, these taxa have a diversity of scale patterns. The ubiquity of the pores indicates a necessary functional role common to all snakes. These pores serve as the surface opening for the generalized sebaceous gland in those reptiles that lack specific glands that allow epidermal exudates access to the scale surface (Chiasson et al., 1989).

The morphological studies of the scales revealed that they
Table 1. Dimensions of scales in Eryx johni, Xenochrophis piscator and Naja naja (in $\mathrm{mm}$ )

\begin{tabular}{llll}
\hline Variables & $\begin{array}{l}\text { Eryx johni } \\
\overline{\mathbf{x}} \pm \text { S.D }\end{array}$ & $\begin{array}{l}\text { Xenochrophis } \\
\text { piscator } \\
\mathbf{X} \pm \text { S.D }\end{array}$ & Naja naja \\
& $11 \pm 0.28$ & $22.1 \pm 0.31$ & $\overline{\mathbf{X}} \pm$ S.D \\
\hline Ventral length & $5 \pm 0.24$ & $7 \pm 0.21$ & $44 \pm 0.29$ \\
Ventral width & $2 \pm 0.13$ & $5 \pm 0.15$ & $5.5 \pm 0.23$ \\
Vertebral length & $2 \pm 0.15$ & $3 \pm 0.14$ & $7 \pm 0.11$ \\
Vertebral width & $4 \pm 0.25$ & $4.5 \pm 0.21$ & $2 \pm 0.10$ \\
Costal length & $4 \pm 0.14$ & $5.1 \pm 0.11$ & $7 \pm 0.27$ \\
Costal width & $52 \pm 1$ & $19 \pm 1$ & $5 \pm 0.15$ \\
No. of longitudinal & & $20 \pm 1$ \\
rows of Dorso-lateral & & & \\
scales (middle region) & & &
\end{tabular}

Table 1a. Anova of Table 1

\begin{tabular}{llllll}
\hline Variables & $\begin{array}{l}\text { Variance } \\
\text { ratio }\end{array}$ & $\begin{array}{l}\text { CD } \\
\text { value }\end{array}$ & Ej Vs Nn & Ej Vs Xp & Xp Vs Nn \\
\hline Ventral length & $3678.13^{*}$ & 0.81 & $33.0^{* *}$ & $11.1^{* *}$ & $21.9^{* *}$ \\
Ventral width & $18.06^{*}$ & 0.72 & 0.5 & $2.0^{* *}$ & $1.5^{* *}$ \\
Vertebral length & $400.00^{*}$ & 0.37 & $5.0^{* *}$ & $3.0^{* *}$ & $2.0^{* *}$ \\
Vertebral width & $13.93^{*}$ & 0.46 & 0.0 & $1.0^{* *}$ & $1.0^{* *}$ \\
Costal length & $39.63^{*}$ & 0.73 & $3.0^{* *}$ & 0.5 & $2.5^{* *}$ \\
Costal width & $18.83^{*}$ & 0.4 & $1.0^{* *}$ & $1.1^{* *}$ & 0.1 \\
No. of longitudinal & $32.56^{*}$ & 0.52 & $4.0^{* *}$ & $6.0^{* *}$ & $2.0^{* *}$ \\
rows of Dorso-lateral & & & & & \\
scales (middle region) & & & & & \\
\hline
\end{tabular}

* - $\mathrm{P}<0.05 ;{ }^{* *}-\mathrm{P}<0.01 ;$ Ej - Eryx johni; $\mathrm{Xp}$ - Xenochrophis Piscator, Nn - Naja naja

are variously shaped in different species. The hexagonal and oval shapes of the scales with their polished nature facilitate easy movement during locomotion. The arrangement of these scales also aids in locomotion. In the three snakes studied they have either overlapping scales with the overlapped side of scales facing posteriorly or backwardly or they have a contiguous scale arrangement. These types of arrangements help easy movement through the surface encountered with little obstruction. The other features of the scales like keeled nature, variations in the anals and caudals, and differences in the dimensions of the scales (Table 1 ) are species specific characters, but may be similar to other species of the same genus.

In the three snakes studied the scale characteristics morphology, arrangement (Images G-Lw) and microornamentation (Images A-Fw ) differ greatly. However, it is difficult to imagine a functional role for such apparently trivial characteristics as keeled or non-keeled scales or a microscopic sculpturing pattern present on the scales. Definitely these characteristics of the scales can be used as a taxonomic tool at least at the genus level or as an indicator of the animals' ecology. Leydig (1868) in his studies on surface sculpturing of several European snakes accepts the significance of the scale characters in systematics.

The micro-ornamentation studies of the ventral and dorsal scales in the three snakes reveal that there occurs a great difference in the scale sculpturing patterns from one species to another. Xenochrophis piscator shows a type of plicate pattern usually observed in aquatic snakes. The plicate pattern appears as waves of reticulate fibres. Each wave boarder (plication) extends as an arch from one longitudinal ridge to 
another. The reticulate pattern appears to be formed by the development of elongated ridges in a generally anteriorposterior orientation. The ridges are much thicker than the floor of the furrows suggesting that they may provide both strength and flexibility to the scale.

Naja naja has a subtype of the cristate pattern which is usually seen in arboreal snakes. Eryx johni has the micro ornamentation pattern closely resembling the canaliculate pattern. The canaliculate pattern is formed by raising the reticulate pattern into longitudinal ridges. The posterior free end (inner side) of the ventral scale also shows certain microscopic modifications like the formation of numerous ridges and channels. Holtzinger-Tenever (1935), Pockrandt (1937) and Hoge \& Santos (1953) are of the opinion that microornamentation differed in different genera of snakes. These patterns have no particular role in locomotion but are species specific and relate to the environmental and habitat preferences of the species. In the present study it was noted that snake scale micro ornamentation was constant over dorsal, dorsolateral and ventral scales of a single species. Picado (1931) was of the opinion that snake scale micro-ornamentation was constant over different regions of a single snake, at different stages in ontogeny, and in different individuals of the same species, but different in different species.

Dowling et al. (1972) based on scanning electron microscopic studies in the snake scales of the genera Bothrops and Crotalus, stated that virtual identity was seen for members of the same species and that meaningful similarities existed at the generic level. They stated that a species may be identified from a single scale. Kimmich \& Blaney (1973) studied the micro-ornamentation of Echis carinatus, particularly the method of sound production in this snake. Gans \& Baic (1977) and Gans (1979) studied the micro-ornamentation of several species of uropeltid snakes. Price (1981) surveyed the microornamentation of over 400 species of snakes, and in a preliminary report (Price, 1981) stated that there was no obvious ecology or habitat related variation and that surface sculpturing patterns were taxonomically significant.

Few studies have suggested certain functional significance for micro-ornamentation. Maderson (1966, 1970) suggested micro-dermatoglyphics (micro-ornamentation) has an intrinsic role in the moulting process. According to Chiasson (1981), scale sculpturing like the presence of stigmata, is thought to act as fasteners holding the outer epidermal layer to the inner layer until it is physically pulled loose during the shedding behaviour of the snake. But most of the snakes studied in the present investigations do not have stigmata. Instead, they have certain ridge like patterns. This low ridge pattern allows sufficient contact between the scales and skin until shedding and thus stigmatal areas are unnecessary in such forms. Chiasson \& Lowe (1989) suggested that the formation of cuplike framework in the scale surface of nerodian aquatic species may better serve oil maintenance on the surface, providing greater efficiency in the reduction of skin permeability and it serves in the overall osmotic barrier. In the aquatic environment of water snakes, such a barrier would advantageously prevent excessive water influx.

Stewart \& Daicel (1973) proposed that micro- ornamentation might be involved in friction problems, which facilitates locomotion. Porter (1967) implied that scale sculpturing of desert reptiles might convert harmful solar radiation to heat.

The most reasonable functional hypothesis, the one which constitutes the only major opposition to using microornamentation pattern as a taxonomic tool was mentioned by Price (1982) who stated that the patterns seemed to be related to the animals' environmental or habitat preferences; that the micro-ornamentation ridge configuration seen in uropeltids facilitates burrowing. However, the scale characteristics including the micro-ornamentation patterns are useful as a taxonomic tool at least at the genus level, besides the functional role to play in the animals' ecology.

\section{Conclusion}

Micro-ornamentation study shows that there occurs a great difference in the scale sculpturing patterns between the three species selected for the present investigation. These patterns can be related to the environmental and habitat preferences of the species. Also, scale characteristics and micro-ornamentation patterns are useful as a taxonomic tool at least at the genus level.

\section{REFERENCES}

Chiason, R.B. (1981). The apial pits of Agkistrodon (Reptilia: serpentes). Journal of Arizona-Nevada Academic Science 16: 69-73.

Chiason, R.B. \& C.H. Lowe (1989). Ultrastructural scale patterns in Nerodia and Thamnophis. Journal of Herpatology 23(2): 109-118.

Chiason, R.B., Bently \& C.H. Lowe (1989). Scale morphology in Agkistrodon and closely related Crotaline genera. Journal of Herpatology 45(4): 430-438.

Dowling, H.G., I. Gilboa, D.E. Gennaro \& J.F. Gennaro (1972). Microdermatoglyphics: A new tool for reptile taxonomy. Herpetology Review 4: 200-204.

Gans, C. (1979). A subterranean snake with a funny tail. Natural History 88: $70-75$.

Gans, C. \& D. Baic (1977). Regional specializations of scale surfaces; relation of texture and biologic role. Science Washington 195(4284): 13481350 .

Hoge, A.R. \& S.P. Santos (1953). Submicroscopic structure of "stratum corneum" of snakes. Science 118: 410-411.

Holtzinger-Tenever, H. (1935). Uber struktubilder des Natternhemdes bei schlangen Ein Hilfsmittel zur systematic. Verh Deut Zoologic (Ges Leipzig) 1935: 88-92.

Joseph, P. (2001). A comparative study on the fiber type composition and enzymatic profile in the locomotory muscles of a few snakes: A histochemical and biochemical investigation in the muscles of Xenochrophis piscator, Naja naja and Eryx johni. Ph.D. Thesis, M.G. University, Kottayam, Kerala.

Kimmich, P.J. \& R.M. Blaney (1973). Scanning electron micrographs of dorsal scales of the saw-scaled viper, Echis carinatus (Schneider). Hiss News Journal 1(3): 85-88.

Leydig, F. (1868). Ueber Organe eines sechsten sinnes. Zugleich als Beitrag zur kenntniss des feineren baues der haut bei Amphibien and Reptilien. Nova Acta Academic Caesar Leop. Carol., Halle 34: 108-110. Maderson, P.F. (1966). Histological changes in the epidermis of the Tokay (Gecko gekko) during the sloughing cycle. Journal of Morphology 119: 39-50.

Maderson, P.F. (1970). Lizard glands and lizard hands: models for evolutionary study. Forma et Function 3: 179-204.

Peterson J.A. (1984). The scale micro architecture of Sphenodon punctatus. Journal of Herpetology 18: 40-47.

Peterson J.A. \& R.L. Bezy (1985). The microstructure and evolution 
of scale surfaces in Xantusid lizards. Herpetologica 41: 298-324.

Picado, T.C. (1931). Epidermal microornaments of the crotalinae. Bulletin of Antivenin Institute of America 4: 104-105.

Pockrandt, D. (1937). Beitrage Zur Histologie der schlongehaut. Zoologic Jahrb Abta Anatomic Ontogen Tierre 62: 275-322.

Porter, W.P. (1967). Solar radiation through the living body walls of vertebrates, with emphasis on desert reptiles. Ecological Monograph 37 273-296.

Price, R.M. (1981). Analysis of the ecological and taxonomic correspondence of dorsal snake scale microdermatoglyphics. Ph.D. Dissertation, New York University, 164pp.

Price, R.M. (1982). Dorsal snake scale microdermatoglyphics: ecological indicator or taxonomic tool. Journal of Herpetology 16: 294-306.

Rubial, R. (1968). The ultra structure of the surface of lizard scales. Copeia 196: 698-704.
Snedcor, G.W. \& W.G. Cohran (1967). Statistical Methods. Oxford and IBH Publishing Co., Bombay.

Stewart, G.R. \& R.S. Daicel (1973). Scanning electron microscopy of scales from different body regions of three lizard species. Journal of Morphology 139: 377-388.

\section{ACKNOWLedgment}

We would like to acknowledge the help of our senior colleague Dr. Thomas T.C., Project Research Officer (Formerly), Department of Physiology, AIIMS, New Delhi for the Electron microscopic studies. The Electron microscopic facility was made available to us by the Department of Anatomy, AIIMS, New Delhi.

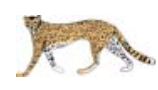

\section{Join MigrantWatch}

MigrantWatch*, an annual countrywide programme to study the movements of nine common winter migrants to India is launched! If you have an interest in the natural world, please help in this collective effort!

All that is required to participate is a basic ability to identify the nine species. Participants keep an eye out for these species around their homes, schools and workplaces, and simply report the first date that they see each one. With a little more effort, participants can also keep a daily record of the target species. A small effort on the part of each one of us added together can lead to huge advances in our understanding of bird migration.

More details on this Citizen Science programme and on how to participate are on the MigrantWatch website:

\section{http://www.ncbs.res.in/citsci/}

The collected information will be made freely available through the web.

The success of MigrantWatch depends on the participation of as many people as possible, from every corner of the country. So please join today, and ask your friends to join too!

With best wishes,

Suhel Quader

for MigrantWatch

<MigrantWatch@ncbs.res.in>

* MigrantWatch is organised by Indian Birds journal in association with the National Centre for Biological Sciences, and with the participation of individuals and organisations across the country. 